\title{
CASE REPORT: RARE CASE OF CLASSICAL HODGKIN'S LYMPHOMA, MIXED CELLULARITY IN A MALE BOY AGED 12 YEARS.
}

1. FCPS (Pediatric Medicine) Consultant Pediatrician THQ Hospital, Rojhan.

2. PGR FCPS (Pediatric Medicine) Postgraduate Residents Department of Pediatric Medicine The Children's Hospital and The Institute of Child Health, Multan

3. FCPS (Pediatric Medicine)

Assistant Professor Department of Pediatrics Unit-II Children Hospital Chandka Medical College/ SMBBMU, Larkana.

Correspondence Address:

Dr. Fazal Ur Rehman

Department of Pediatric Medicine

The Children's Hospital and

The Institute of Child Health, Multan.

fazal171@gmail.com

Article received on:

27/03/2019

Accepted for publication:

20/05/2019

\section{BACKGROUND}

Castleman disease was initially explained in 1956 as a syndrome that is lymphoproliferative, also recognized as angiofollicular lymph node hyperplasia. It is a rare disease with an incidence of about 25 cases / million person annually. ${ }^{1}$ Castleman disease can be classified in subtypes as unicentric or multicentric. Castleman disease may proceed or can be linked to malignant lymphoma that is difficult to diagnose while the treatment is complex. ${ }^{2}$

Hodgkin lymphoma (HL) is a malignancy that is related to lymphoid and can be characterized as Reed-Sternberg cells in the lymph nodes. Prognosis as well as treatment is complex and depends upon the Ann Arbor staging as well as age of the affected patient. ${ }^{3} \mathrm{HL}$ involves 12.1 / million individuals aged less than 20 years, encompassing around $9 \%$ of cases having cancer in this specific age group. ${ }^{4} \mathrm{HL}$ was $1^{\text {st }}$ described in 1832 and since then it has been classified into various subgroups. ${ }^{5}$ Several risk factors depending upon the pathology and prognostic features are documented. The etiology is still not fully understood but factors like EpsteinBarr Virus (EBV), human herpes virus 6 (HHV6), cytomegalovirus (CMV), hepatitis $\mathrm{C}$ virus (HCV) and human immunodeficiency virus (HIV) are said to implicate in the genesis. ${ }^{6}$

WHO divided HL into 2 distinct subtypes, Nodular Lymphocyte Predominant HL (LPHL), 5\% of all $\mathrm{HL}$ cases and classical $\mathrm{HL}$ (cHL) as $95 \%$ of all $\mathrm{HL}$ cases. $\mathrm{CHL}$ is further separated as nodular sclerosis (NSHL), 70\% cases, mixed cellularity (MC), $20 \%$ of cases and lymphocyte depleted HL as $5 \%$ of all HL cases. ${ }^{7}$

\section{CASE PRESENTATION}

The present case was a 12 years old male boy who presented at department of Oncology, Children's Hospital and The Institute of Child Health, Multan, with fever, cough and swelling on the body at multiple sites. The patient started noticing multiple swelling on the neck and profuse sweating about 19 days back. There was associated pallor for that packed cells were transfused. The patient received 
multiple treatments but to no avail. Fine needle aspiration cytology (FNAC) of left cervical lymph node revealed scanty lymphoid cells, suboptimal for definitive diagnosis. Histological examination of the sections revealed effaced architecture of the lymph nodes. There was seen polymorphic lymphoid population, hyalinizing proliferating blood vessels and extensive fibrosis. Picture was suggestive of hyaline vascular castleman disease however the pathologist advised immunochemistry for confirmative diagnosis to rule out lymphoma. Anti HCV and HBsAg were found negative. Typhidot IgG and typhidot IgM were found negative. Other lab reports regarding liver functions, urinary functions and electrolytes were found normal.

CT neck had evidence of enlarged lymph nodes in left submandibular region, level II, level III, level IV, level V, level VI and level VII. Few of them were calcified in supra-clavicular levels. CT Chest showed enlarged lymph nodes noted in prevascular region and along internal mammary artery on right side. Subcentimal lymph nodes were seen in bilateral axillary regions. Patch of consolidation with air bronchograms seen in apical segment of the left lung with adjacent bronchiectatic changes. Another patch of consolidation / collapse noted in posterior basal segment of right lower lobe with pleural thickening and pleural effusion on right side. CT abdomen and pelvis showed hepatosplenomegaly with lymphadenopathy, ascites and lymphomatous deposits in liver, spleen and vertebral bodies.

Cervical lymph node biopsy was ordered. Two friable grayish tissue fragments collectively measuring $1.5 \mathrm{~cm} \times 1.0 \mathrm{~cm}$ was examined. Histological examination disclosed lymph node showing effacement of nodal architecture by a lymphoid neoplasm composed of scattered large mono and binucleated tumor cells having vesicular nuclei and prominent eosinophilic nucleoli. These large cells were present in a mix inflammatory background comprising of lymphocytes, plasma cells, histocytes and eosinophils. Immuno/Histochemical Stains revealed; CD30: positive in large atypical cells, CD15: positive in rare large atypical cells, PAX5: weakly positive in large atypical cells, CD20: negative in large atypical cells, CD: negative in large atypical cells, LCA: negative in large atypical cells. Diagnosis of cervical lymph node biopsy was labeled as classical Hodgkin's Lymphoma, mixed cellularity.

The patient was then put on COPD (Cyclophosphamide, Oncovin, Prednisolone, Dacarbazine) therapy where he started recovery following 8 days of treatment.

\section{DISCUSSION}

Classical Hodgkin's Lymphoma of mixed cellularity is a rare disease specially in children. $\mathrm{HL}$ usually presents with non-tender enlarged lymph nodes which are usually asymmetric, painless and non-adherent to the skin. ${ }^{8}$ Rubbery consistency is associated whereas the neck and supraclavicular region is featured in about $75 \%$ cases as was seen in the present case. $\mathrm{HL}$ is found to spread through lymphatic system. Frequent symptoms found are fever, night sweats and weight loss. We also found fever and profuse sweating in our patient. Other symptoms include cough, pain in the chest area, shortness of breath, abdominal pain and ascites. ${ }^{9}$ Biopsy is noted to be the best method for the confirmatory diagnosis. Fine needle aspiration is not usually indicative of diagnosis that is why excisional biopsy is the most authentic tool. Lymph node examination is usually evident of fibrosis of the tissue architecture. ${ }^{4}$ Early diagnosis, better understanding of the pathophysiology as well as the biology of $\mathrm{HL}$ can assure much better prognosis.

\section{CONCLUSION}

Classical Hodgkin's Lymphoma, mixed cellularity was diagnosed by cervical lymph node biopsy.

\section{Copyright@ 20 May, 2019.}

\section{REFERENCES}

1. Prince $\mathrm{HM}$, Chan $\mathrm{KL}$, Lade $\mathrm{S}$, Harrison S. Update and new approaches in the treatment of Castleman disease. Journal of Blood Medicine 2016; 7:145-58.

2. Talat N, Belgaumkar AP, Schulte KM. Surgery in castlemans disease: A systematic review of $\mathbf{4 0 4}$ published cases. Annals of Surgery 2012; 255(4):677-84. 
3. Filliatre-Clement L, Busby-Venner H, Moulin C, RothGuepin G, Perrot A. Hodgkin lymphoma and castleman disease: When one blood disease can hide another. Case Reports in Hematology 2017; 9423205.

4. Rico JF, Tebbi CK. Hodgkin lymphoma in children: A review. Austin J Pediatr. 2014; 1 (3):1013.

5. Hodgkin. On some morbid appearances of the absorbent glands and spleen. Med Chir Trans. 1832; 17:68-114.

6. Shenoy P, Maggioncalda A, Malik N, Flowers CR. Incidence patterns and outcomes for hodgkin lymphoma patients in the United States. Adv Hematol. 2011; 2011:725219.
7. Swerdlow EC, Harris NL, Jaffe ES, Pileri SA, Stein H, Thiele J, Vardiman J. WHO classification of tumours of haematopoietic and lymphoid tissues, fourth edition. Lyon: IARC Press 2008.

8. Mauch PM, Kalish LA, Kadin M, Coleman CN, Osteen R, Hellman S. Patterns of presentation of Hodgkin disease. Implications for etiology and pathogenesis. Cancer. 1993; 71:2062-2071.

9. Cerci JJ, Trindade E, Buccheri V, Fanti S, Coutinho AM, Zanoni L, et al. Consistency of FDG-PET accuracy and cost-effectiveness in initial staging of patients with Hodgkin lymphoma across jurisdictions. Clinical lymphoma, myeloma \& leukemia. 2011; 11:314-320.

\begin{tabular}{|c|c|c|c|}
\hline \multicolumn{3}{|c|}{ AUTHORSHIP AND CONTRIBUTION DECLARATION } \\
\hline Sr. \# & Author(s) Full Name & \multicolumn{1}{|c|}{ Contribution to the paper } & Author(s) Signature \\
\hline 1 & Muhammad Ejaz Mazari & $\begin{array}{l}\text { Literature review, case } \\
\text { handling. } \\
\text { Literature review, case } \\
\text { handling, Drafting. } \\
\text { Case discussion, Proof reading }\end{array}$ \\
\hline 3 & Fazal Ur Rehman & Asif Ali Khuhro & \\
\hline
\end{tabular}

